\title{
Concrete cover tensile capacity of corroded reinforced concrete
}

\author{
Yanlong Zhang and Ray Kai Leung Su ${ }^{*}$
}

Department of Civil Engineering, The University of Hong Kong, Pokfulam Road, Hong Kong, PRC

\begin{abstract}
In this paper, the concrete cover tensile (CCT) capacity of cracked concrete caused by
\end{abstract} reinforcement corrosion is investigated. A newly developed double-cylinder model with the consideration of concrete confinement effects is used to evaluate the critical expansive pressure of the corrosion products necessary to cause unstable cover crack propagation in corroded reinforced concrete. After considering the critical pressures associated with wide ranges of tensile capacities of concrete, reinforcement diameters and cover thicknesses, an empirical critical expansion pressure function is determined by the least squares method. The CCT capacity of cracked concrete is obtained by considering the equilibrium of expansive pressure and concrete resistant tensile force at the limiting stage. A generic relationship between CCT capacity and concrete cover in a bilinear form, which is suitable for the design, analysis and modeling of the problems related to reinforcement bar corrosion induced and other internal expansion-caused cover cracking, is proposed for the first time. Parametric studies are conducted to investigate the effects of the tensile strength of concrete and cover thickness on the critical expansive pressure and CCT capacity.

Keywords: concrete cover; concrete cover tensile capacity; characteristic cover thickness; critical expansive pressure; reinforcement corrosion

\footnotetext{
* Corresponding author. Tel.:+852 28592648

E-mail address: klsu@hku.hk
} 


\section{Introduction}

Deleterious reactions in reinforced concrete (RC) may cause volumetric expansion in one

or more of its phases [1], thereby affecting the serviceability, strength, durability, integrity and life span of RC structures [2]. In plain concrete, internal expansion can result from physical attacks associated with salt precipitation and ice formation, and chemical attacks due to alkali-aggregate reaction, sulfate attack and delayed ettringite formation. In RC structures, corrosion of the reinforcement bar due to the electrochemical reaction can lead to volumetric expansion as the volume of the generated corrosion products is larger than that of the original steel [1].

Concrete is particularly sensitive to tensile stresses; small volumetric expansion can cause cover cracking and even spalling of the surrounding concrete. The development of expansive pressure in concrete cover over time due to reinforcement corrosion is illustrated in Fig. 1. During the steel corrosion and concrete cover cracking process, the corrosion products filling concrete pore at steel/concrete interface happens spontaneously with accumulating between steel and concrete as corrosion layer [3-5]. The expansive pressure caused by the corrosion produces in the steel/concrete interface increases with time. When the expansive pressure reaches the maximum value, it is defined herein as the critical expansive pressure, and unstable crack propagation will occur through the whole cover to cause the cover failure. The serviceability, durability, and residual life analysis of RC structures are largely dependent on the stress conditions of the concrete cover. It is imperative, therefore, to know the maximum tensile force that the concrete cover can resist during the unstable crack growth stage, or in other words, the concrete cover tensile (CCT) capacity. 
Traditionally, the CCT capacity was simply taken as a product of concrete tensile strength and the cover thickness [6-11] without considering concrete cracking. This approach may be suitable for uncracked concrete but would overestimate the CCT capacity when unstable crack propagation occurs in the cover zone, as only a small portion of concrete cover has reached its tensile strength capacity [12].

In this study, critical expansive pressure and CCT capacity of corroded reinforcement concrete are determined by a newly developed double-cylinder model [13]. A generic relationship between CCT capacity and concrete cover in a bilinear form is proposed for the first time. A numerical parametric study is carried out to investigate the effects of tensile strength of concrete and cover thickness on the critical expansive pressure and CCT capacity. It is worth noting that the equations and findings obtained from this study are applicable to the problems related to general volumetric expansion in concrete caused by not only reinforcement bar corrosion but also salt precipitation and ice formation.

\section{The analytical model}

To simulate the effect of concrete cracking due to the corrosion of reinforcement, a doublecylinder model [13] developed by the authors was employed. This model features: (1) incorporating residual tensile stress in cracked concrete, (2) considering the stiffness contribution from both reinforcement and corrosion products (i.e. the corrosion products and non-corroded steel are combined together to form a steel-corrosion product composite), (3) modeling the volume compatibility condition in the steel-rust-concrete interface, and (4) simulating the continuity of stress and strain on the common boundary between the 
1 uncracked and cracked concrete cylinders. This model is suitable for the present analysis as it

2 has considered the concrete confinement effect outside the concrete cylinders and the

3 boundary effect arising from the thickness difference between concrete covers. Also, it is

4 capable of predicting the time to cracking and the corrosion-caused expansive pressure,

5 which are relevant to this study.

6 The main principle of this double-cylinder model is briefly presented herein. The

7 reinforcement corrosion problem considered by this model is shown in Fig. 2a. When the

8 reinforcing bar is placed below the mid-depth of the concrete section, $c_{\mathrm{b}}$ and $c_{\mathrm{t}}$ are the

9 thicknesses of the thinner (bottom) and thicker (top) covers, respectively. In the figure, $P_{\text {rust }}$ is the expansive pressure caused by the expansion of the corrosion products, $d_{0}$ is the thickness

11 of the porous zone, $D$ is the initial diameter of the reinforcing bar embedded in the concrete,

$12 r_{0}$ is the crack front, and $t_{\mathrm{c}, \mathrm{e}}$ is the time to cover cracking for the actual case. The first analytical model, as shown in Fig. 2b, is the traditional model widely adopted in the literature.

14 The radius of the concrete cylinder is the same as the thickness of the thinner cover, and is equal to $D / 2+d_{0}+c_{\mathrm{b}, 0}$, where $c_{\mathrm{b}, 0}=c_{\mathrm{b}}$. $P_{\mathrm{c}, 0}$ is the confining pressure provided by the uncracked concrete cylinder, and $\sigma_{\theta, 0}(r)$ is the residual tensile stresses provided by the cracked concrete cylinder. The critical expansive pressure necessary to cause cover cracking predicted by this model is likely to be underestimated as the confinement pressure outside the cylinder has been ignored.

To yield a more accurate prediction, the second model, as depicted in Fig. 2c, with a cylinder radius equal to $D / 2+d_{0}+c_{\mathrm{b}, 1}\left(c_{\mathrm{b}, 1} \geq c_{\mathrm{b}, 0}\right)$, which is larger than or equal to that of the first model, is introduced. The required radius of the cylinder has been obtained by calibrating the 
1 computed time to cover cracking with the available experimental results [13].

2 The analytical solutions of these two models can be solved by considering the following

3 conditions: (1) the force equilibrium in the tangential direction, (2) volume expansion in the

4 steel-rust-concrete interface, (3) deformation compatibility in the steel-rust-concrete interface,

5 (4) the force equilibrium in the radial direction, and (5) bilinear relationship of the tension

6 softening curve of concrete. Full details of the solution procedure can be found in reference

$7 \quad[13]$.

8 By comparing the predicted expansive pressure obtained from the second (more accurate)

9 model with that from the first model, the confinement adjustment factors for corrosioncaused expansive pressure $\psi_{p}$ derived in Ref. [13] is reproduced in Eq. (1).

$$
\psi_{p}=\left\{\begin{array}{lc}
0.08 \frac{C_{\mathrm{t}}}{C_{\mathrm{b}}}+0.92 & 1 \leq c_{\mathrm{t}} / c_{\mathrm{b}} \leq 3 \\
1.15 & 3<c_{\mathrm{t}} / c_{\mathrm{b}}
\end{array}\right.
$$

This equation takes into account the confinement and boundary effects outside the concrete

cylinder of the first model. The corrosion-caused expansive pressure $P_{\text {rust, } 1}$ of the second (more accurate) model can be conveniently obtained from that of the first model $P_{\text {rust }, 0}$, i.e.,

$$
P_{\text {rust }, 1}=\psi_{p} P_{\text {rust }, 0}
$$

This double-cylinder model is capable of predicting the time to cracking, the corrosioncaused expansive pressure and the amount of iron consumed during the corrosion-caused cracking process.

\section{Critical expansive pressure}


Su and Zhang [13] have shown that the variation of the elastic modulus of rust and the type of corrosion products has no influence on the critical expansive pressure. Obviously, the ratio

3 defining the volume of corrosion products diffused into the cracks also has no influence on

4 the critical expansive pressure. This is because the critical expansive pressure depends only

5 on the material properties of concrete (i.e., the modulus of elasticity, the tensile strength $f_{\mathrm{t}}$,

6 and the stress-strain relationship in tension) and the geometrical properties of cover (i.e., the

7 cover thickness and reinforcing bar diameter). In this study, the modulus of elasticity of

8 concrete is fixed and the stress-strain relationship of concrete under tension varies only with

9 the tensile strength of concrete, thus the critical expansive pressure only varies with the tensile strength of concrete, cover thickness, and reinforcing bar diameter.

11 The effects of cover thickness on the predicted critical expansive pressure for different tensile strength of concrete and different reinforcing bar diameters are shown in Fig. 3 for the first model, i.e., when $c_{\mathrm{b}}=c_{\mathrm{t}}$. It is found that the critical expansive pressure $P_{\text {rust,0c }}$ can be expressed as a linear function of the cover thickness as shown in Eq. (3)

$$
P_{\text {rust }, 0 \mathrm{c}}=\eta_{1} c_{\mathrm{b}, 0}+\eta_{2}
$$

where $\eta_{1}$ and $\eta_{2}$ are the computed pressure coefficients for different combinations of tensile strength of concrete and bar diameters as listed in Table 1.

Using Eq. (3), a set of critical expansive pressures against different combinations of cover thickness, tensile strength of concrete and bar diameter can be generated. By the least squares method, the general form of the critical expansive pressure, which is an empirical function of cover thickness, tensile strength of concrete and bar diameter, is given in Eq. (4). 
1

$$
\begin{aligned}
P_{\text {rus }, 0 c}^{C} & =-0.00338 f_{\mathrm{t}} D c_{\mathrm{b}, 0}+0.11308 f_{\mathrm{t}} c_{\mathrm{b}, 0}+0.00118 D^{2} c_{\mathrm{b}, 0}-0.03689 D c_{\mathrm{b}, 0}+0.02319 D^{2} f_{\mathrm{t}} \\
& -0.68993 f_{\mathrm{t}} D+3.9058 f_{\mathrm{t}}-0.10141 D^{2}+0.22599 c_{\mathrm{b}, 0}+3.0511 D-15.418
\end{aligned}
$$

Fig. 4 compares the critical expansion pressures $\left(P_{\text {rust,oc }}^{\mathrm{C}}\right)$ obtained directly from Eq. (4) and those $\left(P_{\text {rust,oc }}\right)$ determined by the double-cylinder model [13]. A very good agreement

4 between $P_{\text {rust,oc }}$ and $P_{\text {rust,oc }}^{\mathrm{C}}$ can be observed.

Although the critical expansive pressure in Eq. (4) is obtained from corrosion-caused cover cracking, it can be extended to yield the critical expansive pressure caused by other types of volumetric expansions, such as salt precipitation and ice formation, as long as the internal expansive pressure can be assumed to be uniformly distributed along a circular circumference. In such case, the critical expansive pressure is only dictated by the tensile strength of concrete, cover thickness, and bar diameter.

Using Eq. (2), the actual critical expansive pressure of the second (more accurate) model with the consideration of the confinement and boundary effects can be expressed as,

$$
P_{\text {rust, }, \text { c }}^{C}=\psi_{p} P_{\text {rust, }, 0}^{C}
$$

\section{Generic relationship of CCT capacity and concrete cover}

When the cover thickness is small and cracking occurred in concrete cover, the residual tensile stress distribution in the concrete cover can be presented in Fig. 5a. It can be seen that all concrete stress in the cover is almost equal to the tensile strength of concrete $f_{\mathrm{t}}$. By integrating the residual tensile stress along the thickness of the cover, the CCT capacity $F_{\mathrm{cc}, 0}$ of the first model can be approximately taken as

$$
F_{\mathrm{cc}, 0}=f_{\mathrm{t}} c_{\mathrm{b}, 0}
$$

As the cover thickness increases, Eq. (6) is no longer suitable for the determination of CCT 
1 capacity, as the residual tensile stresses near the rust-concrete surface and near the cover

2 surface are reduced to much less than $f_{\mathrm{t}}$. The tensile stress distribution in the concrete cover is

3 illustrated in Fig. 5b. The CCT capacity $F_{\mathrm{cc}, 0}$ of the first model can be obtained by either

4 integrating the residual tensile stress or considering the equilibrium force between the critical

5 expansion force and the total tensile force provided by the residual tensile stress. Hence,

6

7 and

$$
F_{\mathrm{cc}, 0}=P_{\mathrm{rust}, 0 \mathrm{c}}^{\mathrm{C}} a=\gamma_{0} f_{\mathrm{t}} c_{\mathrm{b}, 0}
$$

8 where $\gamma_{0}$ is defined as a CCT coefficient of the first model. As $a=D / 2+d_{0}$ and $D / 2>>d_{0}$, Eq.

$9 \quad$ (7) can be approximated as

$$
\gamma_{0}=\frac{P_{\mathrm{rust}, 0 \mathrm{c}}^{\mathrm{C}} a}{f_{\mathrm{t}} c_{\mathrm{b}, 0}} \leq 1
$$


1

$$
\begin{aligned}
\gamma_{0}= & -0.00169 D^{2}+0.05654 D+\frac{0.00059 D^{3}-0.018445 D^{2}+0.112995 D}{f_{\mathrm{t}}} \\
& +\frac{0.011595 D^{3}-0.344965 D^{2}+1.9529 D}{c_{\mathrm{b}, 0}}-\frac{0.050705 D^{3}-1.52555 D^{2}+7.709 D}{f_{\mathrm{t}} c_{\mathrm{b}, 0}}
\end{aligned}
$$

2 Then, the CCT capacity of the first model can be expressed as

$$
\left\{\begin{array}{lr}
F_{\mathrm{cc}, 0}=f_{\mathrm{t}} c_{\mathrm{b}, 0} & c_{\mathrm{b}, 0} \leq c_{\mathrm{b}, 0 \mathrm{c}} \\
F_{\mathrm{cc}, 0}=\gamma_{0} f_{\mathrm{t}} c_{\mathrm{b}, 0} & c_{\mathrm{b}, 0}>c_{\mathrm{b}, 0 \mathrm{c}}
\end{array}\right.
$$

4 According to Eq. (11), the generic relationship of CCT capacity and cover thickness in a

5 bilinear form is shown in Fig. 6.

6

Using Eq. (5), the characteristic cover thickness $c_{\mathrm{b}, 1 \mathrm{c}}$, CCT coefficient $\gamma_{1}$ and the CCT

capacity $F_{\mathrm{CC}, 1}$ for the second model, with consideration of the concrete confinement and boundary effects, can be derived as follows:

9

$$
\begin{gathered}
c_{\mathrm{b}, 1 \mathrm{c}}=\frac{\left(0.011595 D^{3}-0.344965 D^{2}+1.9529 D\right) f_{\mathrm{t}}-0.050705 D^{3}+1.52555 D^{2}-7.709 D}{\left(\frac{1}{\psi_{p}}+0.00169 D^{2}-0.05654 D\right) f_{\mathrm{t}}-0.00059 D^{3}+0.018445 D^{2}-0.112995 D} \\
\gamma_{1}=\psi_{p}\left[-0.00169 D^{2}+0.05654 D+\frac{0.00059 D^{3}-0.018445 D^{2}+0.112995 D}{f_{\mathrm{t}}}+\right.
\end{gathered}
$$

$$
\left.\frac{0.011595 D^{3}-0.344965 D^{2}+1.9529 D}{c_{\mathrm{b}, 0}}-\frac{0.050705 D^{3}-1.52555 D^{2}+7.709 D}{f_{\mathrm{t}} c_{\mathrm{b}, 0}}\right]
$$

$$
\begin{cases}F_{\mathrm{cc}, 1}=f_{\mathrm{t}} c_{\mathrm{b}, 0} & c_{\mathrm{b}, 0} \leq c_{\mathrm{b}, 1 \mathrm{c}} \\ F_{\mathrm{cc}, 1}=\gamma_{1} f_{\mathrm{t}} c_{\mathrm{b}, 0} & c_{\mathrm{b}, 0}>c_{\mathrm{b}, 1 \mathrm{c}}\end{cases}
$$

\section{Parametric study and discussion}

In this section, the effects of tensile strength of concrete and cover thickness on the critical expansive pressure, characteristic cover thickness, CCT coefficient and CCT capacity for the 
$2 \quad 5.1$ Effects of tensile strength of concrete

3 The effects of the tensile strength of concrete on the critical expansive pressure, 4 characteristic cover thickness, CCT coefficient and CCT capacity are shown in Fig. 7.

5 Without the loss of generosity, the bar diameter is taken as $16 \mathrm{~mm}$ and cover thickness is 6 taken as $51 \mathrm{~mm}$ in the following study.

7 The critical expansive pressure as a function of the tensile strength of concrete is shown in

8 Fig. 7a. It was found that the critical expansive pressure increases with an increase in the 9 tensile strength of concrete, which concurs with the work of Su and Zhang [13] and Zhao et 10 al. [14]. It is understandable that the larger the concrete tensile strength is, the larger the 11 critical expansive pressure.

Fig. 7b presents the effect of the tensile strength of concrete on the characteristic cover thickness. The figure shows that the characteristic cover thickness is reduced with an increase

14 in the tensile strength of concrete. This is because when comparing the tension softening curves of normal and high strength concrete, the rate of reduction of the residual tensile strength with respect to the crack opening displacement is faster for higher strength concrete [15]. Hence, with similar crack opening displacements near the steel-rust-concrete surface, the ratio of the residual tensile force at the cover to the maximum tensile capacity $\left(f_{\mathrm{t}} c_{\mathrm{b}, 0}\right)$, i.e., the CCT coefficient, is less for high strength concrete.

Fig. 7c shows the effect of the tensile strength of concrete on the CCT coefficient. The trends of Fig.7b and 7c are the same. The explanation given for the previous effect (the effect of the tensile strength of concrete on the characteristic cover thickness) can also be applied to 
this effect.

Fig. $7 d$ shows the effect of the tensile strength of concrete on the CCT capacity. It is found that the CCT capacity increases with the tensile strength of concrete, which is in line with the work of Liu and Weyers [6] and Zhao and Jin [10].

\subsection{Effects of cover thickness}

Fig. 8 shows the effects of cover thickness on the critical expansive pressure, characteristic cover thickness, CCT coefficient and CCT capacity. Without the loss of generosity, the tensile strength of concrete and the bar diameter are taken as $3.3 \mathrm{MPa}$ and $16 \mathrm{~mm}$, respectively, in the following study and the illustration is also equally applicable to other bar sizes from 12 $\mathrm{mm}$ to $20 \mathrm{~mm}$.

The critical expansive pressure versus cover thickness is shown in Fig. 8a. It can be seen that the critical expansive pressure increases with that of the cover thickness. This observation is supported by the findings from Su and Zhang [13] and Chernin et al. [12, 16]. This is because the wall thickness of the concrete cylinder generally increases with the cover thickness; a concrete cylinder with a thicker wall can provide a higher bearing pressure to resist the expansive pressure generated from the corrosion product.

Fig. 8b presents the CCT coefficient versus cover thickness. It is found that as the cover thickness increases, the CCT coefficient decreases, which is in line with the finding of Chernin and Val [12]. This is because for a cracked cover, the residual tensile stress near the cover surface will decrease as the cover thickness increases. Furthermore, the crack tip has been propagated toward the cover surface from the reinforcement bar surface, and the 
1 residual tensile stress in the concrete near the steel-rust-concrete surface is reduced as well.

2 Both factors lead to a reduction of the CCT coefficient with the increase in cover thickness.

3 Fig. 8c displays the variation of CCT capacity with cover thickness. This figure shows that

4 the CCT capacity increases as the cover thickness increases. This finding is supported by the

5 work of Zhao and Jin [10]. It is understandable as a higher cover thickness can resist more

6 tensile loads in the concrete cover.

7

\section{6. Conclusions}

9 In this study, a semi-analytical procedure developed by a double-cylinder model is used to 10 evaluate the concrete cover tensile (CCT) capacity and the critical expansive pressure necessary to cause cover cracking of the corroded reinforced concrete. The main findings of this study are summarized below.

(1) The generic relationship between the CCT capacity and the thickness of the concrete cover is presented in a bilinear form for bar sizes from $12 \mathrm{~mm}$ to $20 \mathrm{~mm}$. The characteristic cover thickness derived can be used to demarcate the condition where the widely adopted assumption of full CCT capacity is not valid. The generic relationship can be applied to design, analysis, modeling, and evaluation of tension-caused cover cracking.

(2) The CCT coefficient, which can facilitate designers, engineers, or researchers to determine the CCT capacity, has been expressed in terms of the tensile capacity of concrete, reinforcement bar diameter (with bar sizes from $12 \mathrm{~mm}$ to $20 \mathrm{~mm}$ ), and thickness of concrete cover (from $25 \mathrm{~mm}$ to $80 \mathrm{~mm}$ ).

(3) A numerical parametric study has been conducted to investigate the effects of tensile strength of concrete and cover thickness on the critical expansive pressure, the characteristic 
cover thickness, CCT coefficient, and CCT capacity.

(4) It is worth noting that as the critical expansive pressure is only dependent on the material properties of concrete and the geometrical properties of cover, the results and equations presented in this paper are applicable to the problems related to general volumetric expansion in concrete caused by not only reinforcement bar corrosion but also salt precipitation and ice formation.

\section{Acknowledgement}

The research described here was supported by the Seed Funding Program for Applied Research (2015-16) of The University of Hong Kong.

\section{References}

[1] R. Piltner, Paulo J.M. Monteiro, Stress analysis of expansive reactions in concrete, Cement and Concrete Research 30 (2000) 843-848.

[2] K. Bhargava, A.K. Ghosh, Y. Mori, S. Ramanujam, Model for cover cracking due to rebar corrosion in RC structures, Engineering Structures 28 (2006) 1093-1109.

[3] Y.X. Zhao, Y.Y. Wu, W.L. Jin, Distribution of millscale on corroded steel bars and penetration of steel corrosion products in concrete, Corrosion Science 66 (2013) 160-168.

[4] Y.X. Zhao, H.J. Ding, W.L. Jin, Development of the corrosion-filled paste and corrosion layer at the steel/concrete interface, Corrosion Science 87 (2014) 199-210.

[5] Y.X. Zhao, J.F. Dong, Y.Y. Wu, W.L. Jin, Corrosion-induced concrete cracking model considering corrosion product-filled paste at the concrete/steel interface, Construction and Building Materials 116 (2016) 273-280.

[6] Y. Liu, R.W. Weyers, Modeling the time-to-corrosion cracking in chloride contaminated reinforced concrete structures, ACI Materials Journal 95 (1998) 675-681.

[7] K.G. Papakonstantinou, M. Shinozuka, Probabilistic model for steel corrosion in reinforced concrete structures of large dimensions considering crack effects, Engineering Structures 57 (2013) 306-326. 
1 [8] Z.P. Bažant, Physical model for steel corrosion in concrete sea structures-application, Journal of the Structural Division, 105(6) (1979) 1155-1166.

3 [9] T. El Maaddawy, K. Soudki, A model for prediction of time from corrosion initiation to corrosion cracking, Cement \& Concrete Composites 29 (2007) 168-175.

5 [10] Y.X. Zhao, W.L. Jin, Modeling the amount of steel corrosion at the cracking of concrete cover, Advances in Structural Engineering 9 (5) (2006) 687-696.

7 [11] R. Tepfers, Cracking of concrete cover along anchored deformed reinforcing bar, Magazine of Concrete Research 31(106) (1979) 3-12.

9 [12] L. Chernin, D.V. Val, Prediction of corrosion-induced cover cracking in reinforced concrete structures, Construction and Building Materials 25 (2011) 1854-1869.

[13] R.K.L. Su, Y.L. Zhang. A double-cylinder model incorporating confinement effects for the analysis of corrosion-caused cover cracking in reinforced concrete structures, Corrosion Science 99 (2015) 205-218.

[14] Y.X. Zhao, J. Yu, W.L Jin, Damage analysis and cracking model of reinforced concrete structures with rebar corrosion, Corrosion Science 53 (2011) 3388-3397.

[15] H.H. Chen, R.K.L. Su, Tension softening curves of plain concrete, Construction and Building Materials 44 (2013) 440-451.

[16] L. Chernin, D.V. Val, K.Y. Volokh, Analytical modelling of concrete cover cracking caused by corrosion of reinforcement, Materials and Structures 43(4) (2010) 543-556. 
Table 1. Computed pressure coefficients

\begin{tabular}{|c|c|c|c|}
\hline$f_{\mathrm{t}}(\mathrm{MPa})$ & $D(\mathrm{~mm})$ & $\eta_{1}$ & $\eta_{2}$ \\
\hline \multirow{5}{*}{2.8} & 12 & 0.15395 & 3.62721 \\
\hline & 14 & 0.12217 & 4.15257 \\
\hline & 16 & 0.10472 & 4.17258 \\
\hline & 18 & 0.09547 & 3.40760 \\
\hline & 20 & 0.08464 & 3.42711 \\
\hline \multirow{5}{*}{3.3} & 12 & 0.19322 & 3.0159 \\
\hline & 14 & 0.15815 & 3.4478 \\
\hline & 16 & 0.13064 & 3.8656 \\
\hline & 18 & 0.12058 & 3.0189 \\
\hline & 20 & 0.10366 & 3.27054 \\
\hline \multirow{5}{*}{3.8} & 12 & 0.22738 & 2.74702 \\
\hline & 14 & 0.19138 & 2.94717 \\
\hline & 16 & 0.16170 & 3.27970 \\
\hline & 18 & 0.14754 & 2.54252 \\
\hline & 20 & 0.12877 & 2.77035 \\
\hline \multirow{5}{*}{4.3} & 12 & 0.26111 & 2.10374 \\
\hline & 14 & 0.22321 & 2.14342 \\
\hline & 16 & 0.19427 & 2.20555 \\
\hline & 18 & 0.17120 & 2.29022 \\
\hline & 20 & 0.15212 & 2.40077 \\
\hline
\end{tabular}




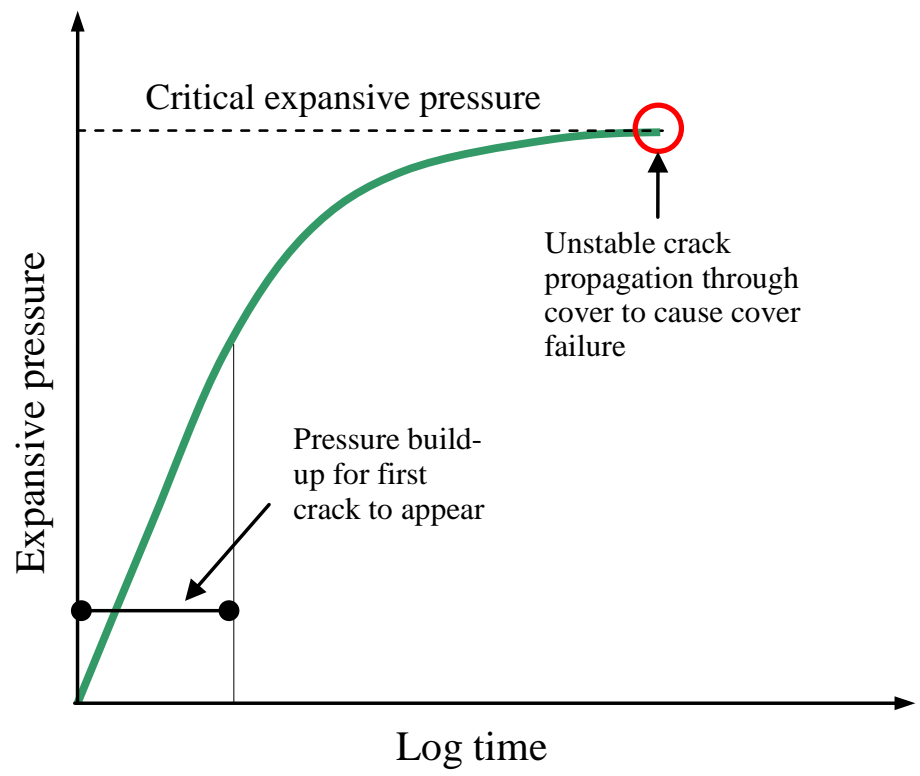

Fig. 1. Illustration of the development of expansive pressure against time

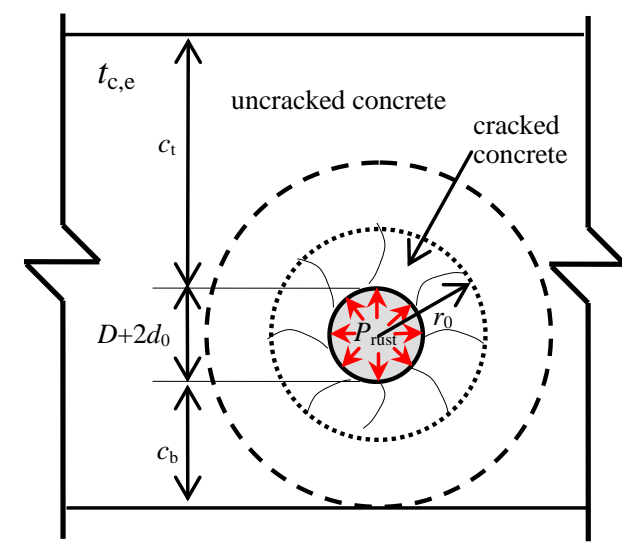

(a)

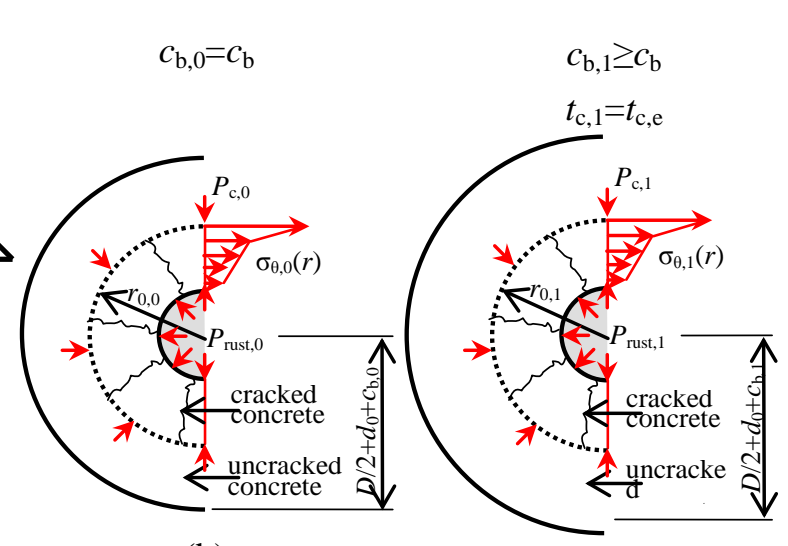

(b)

(c)

Fig. 2. The corrosion problem: (a) the actual case, (b) the traditional analytical model (the first model), and (c) the equivalent analytical model (the second model) 

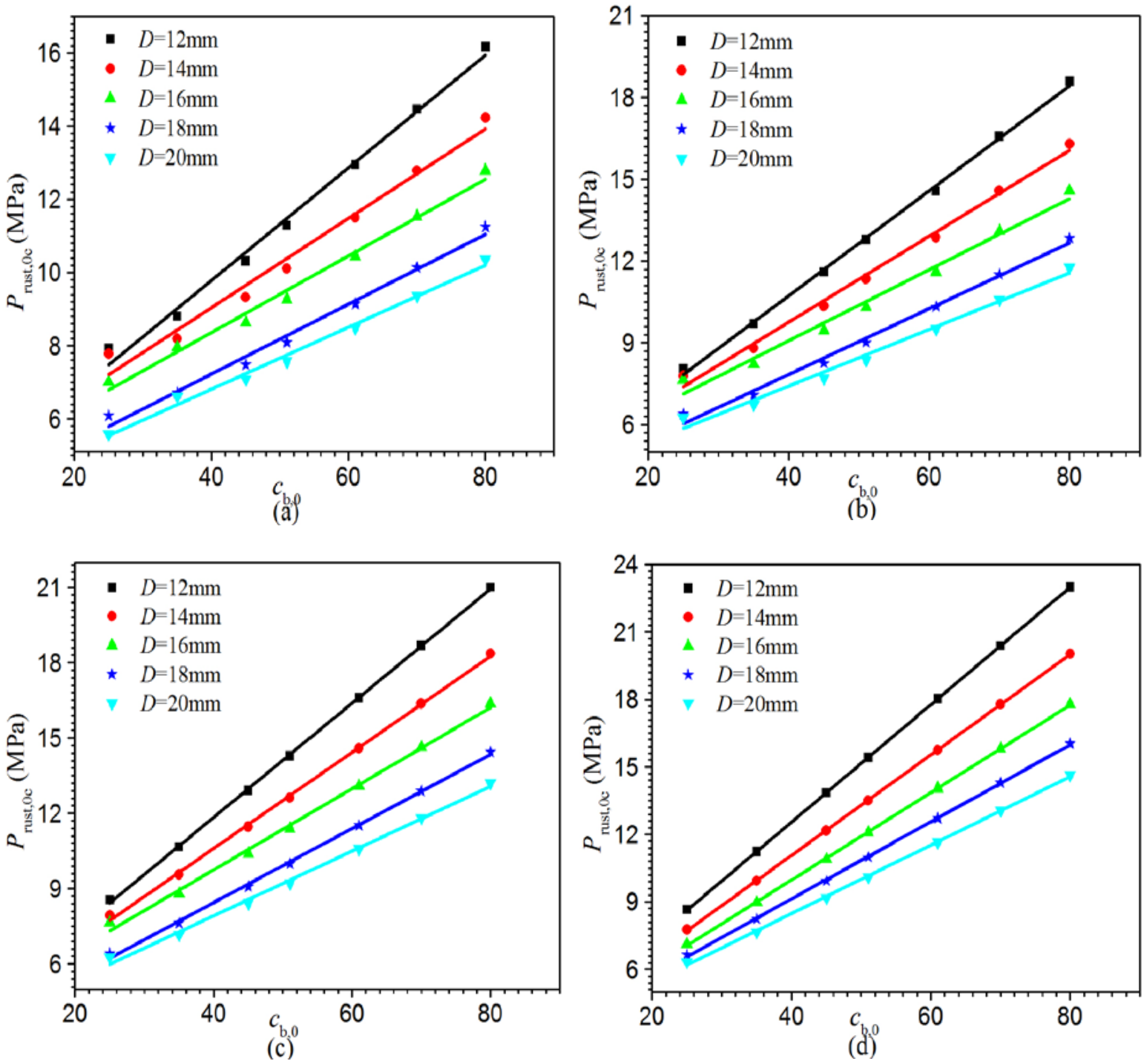

Fig. 3. Relationships between cover thickness with expansive pressures for different concrete tensile strengths and different reinforcement diameters : (a) $f_{\mathrm{t}}=$

2.8 MPa, (b) $f_{\mathrm{t}}=3.3 \mathrm{MPa}$, (c) $f_{\mathrm{t}}=3.8 \mathrm{MPa}$ and (d) $f_{\mathrm{t}}=4.3 \mathrm{MPa}$ 


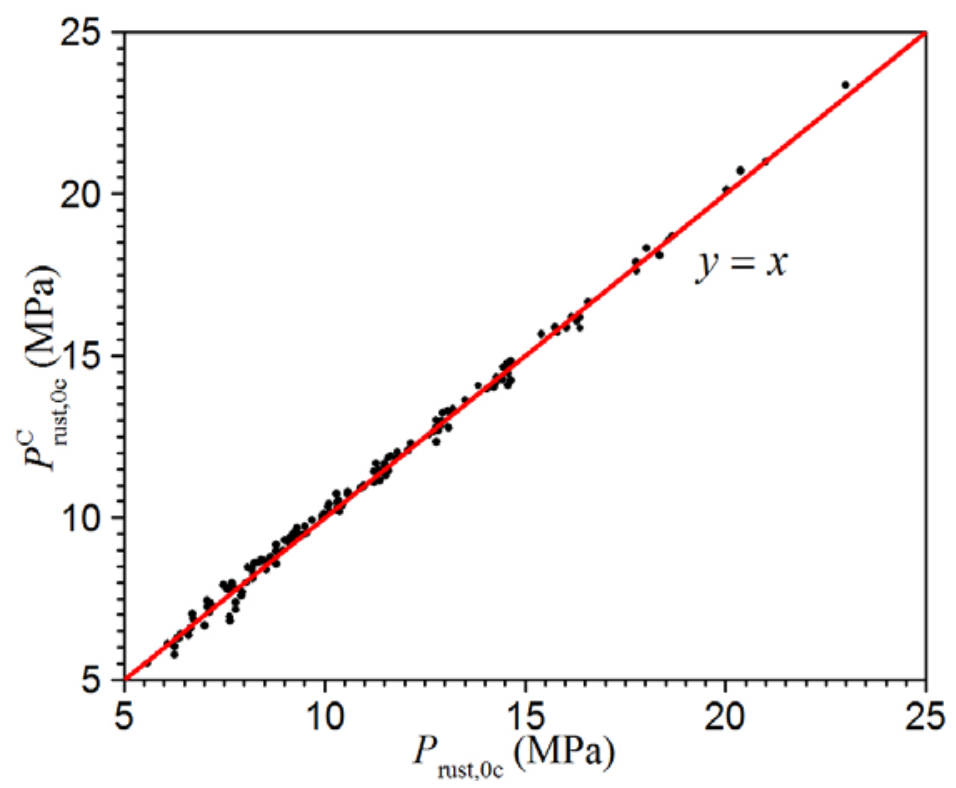

Fig. 4. Comparison of $P_{\text {rust,oc }}$ to $P_{\text {rust,oc }}^{\mathrm{C}}$

2

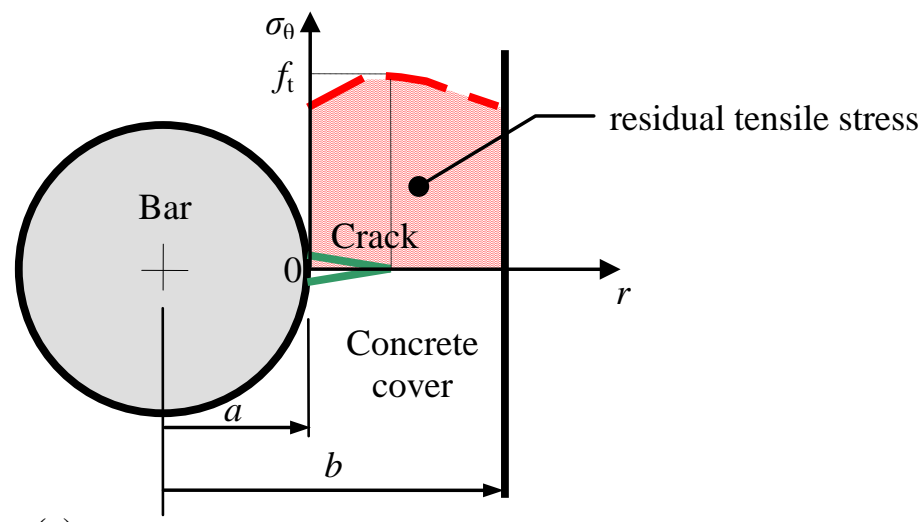

(a)

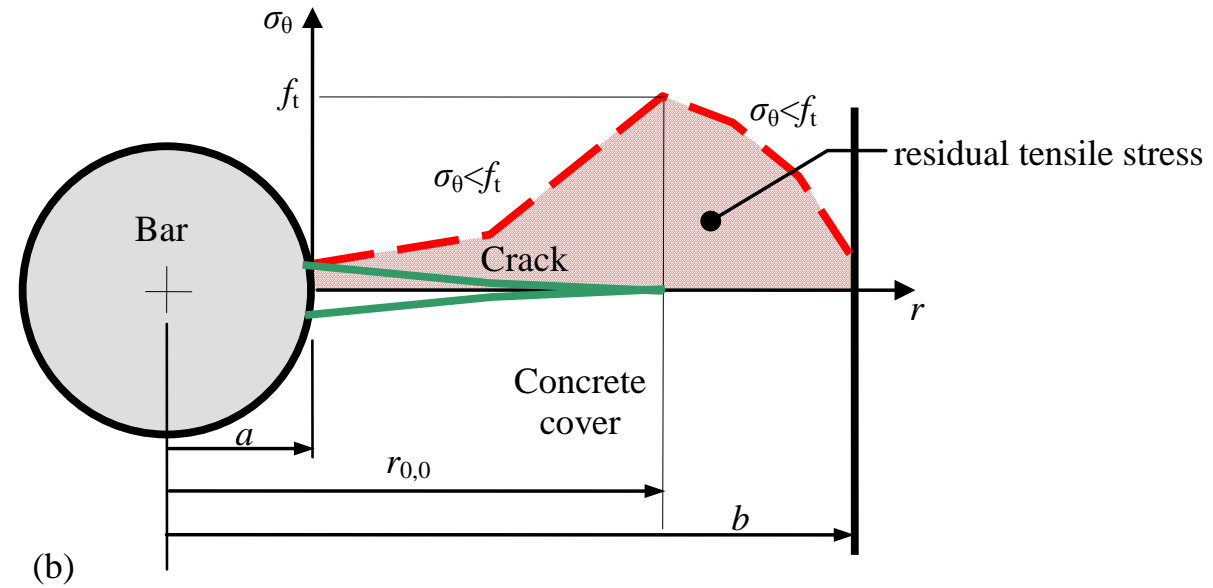

Fig. 5. Tensile stress distribution in cracked concrete: (a) $c_{\mathrm{b}, 0} \leq c_{\mathrm{b}, 0 \mathrm{c}}$ and (b) $c_{\mathrm{b}, 0}>c_{\mathrm{b}, 0 \mathrm{c}}$ 


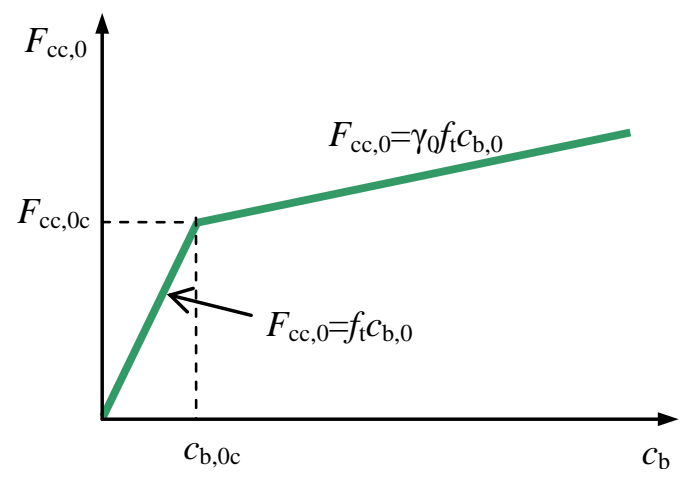

Fig. 6. Generic relationship between the CCT capacity and concrete cover 2
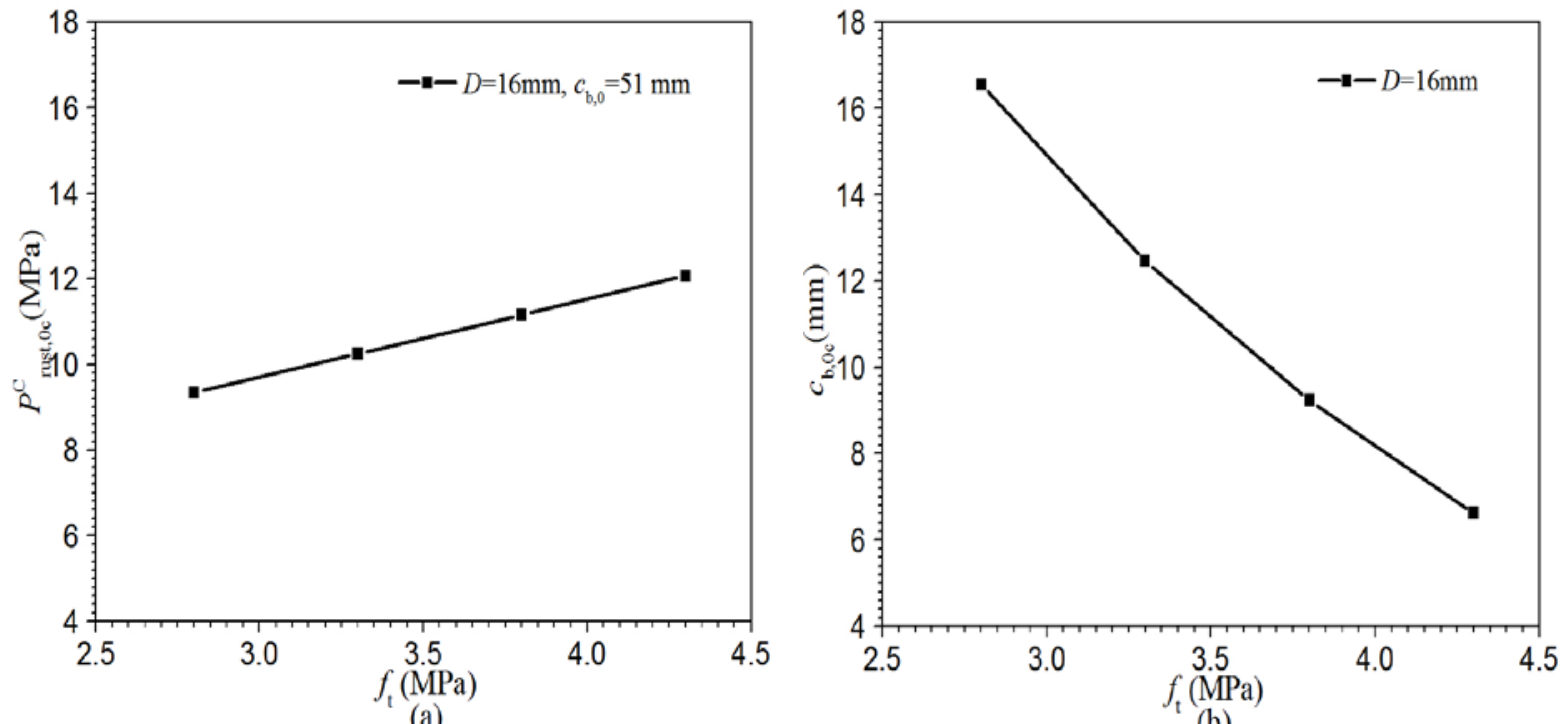

(a)

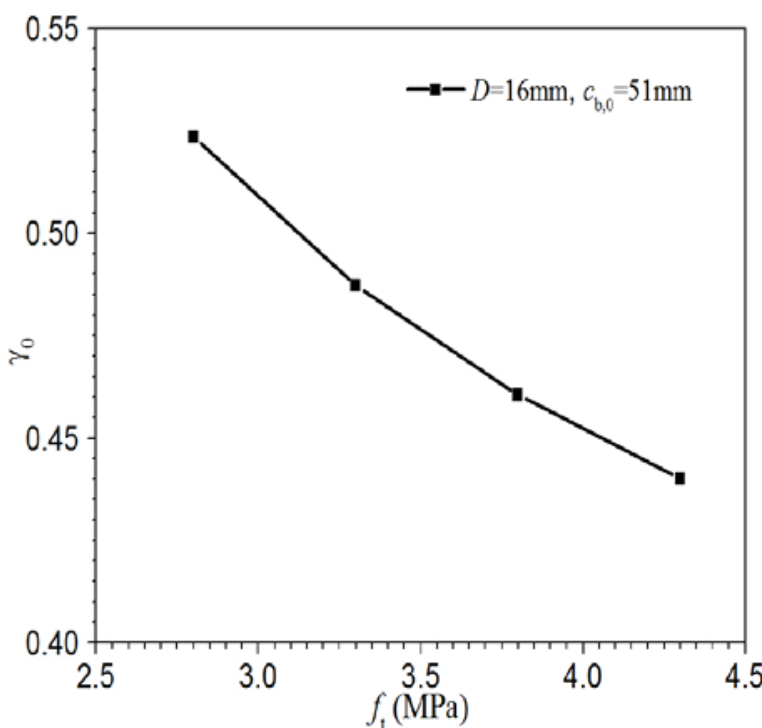

(c)

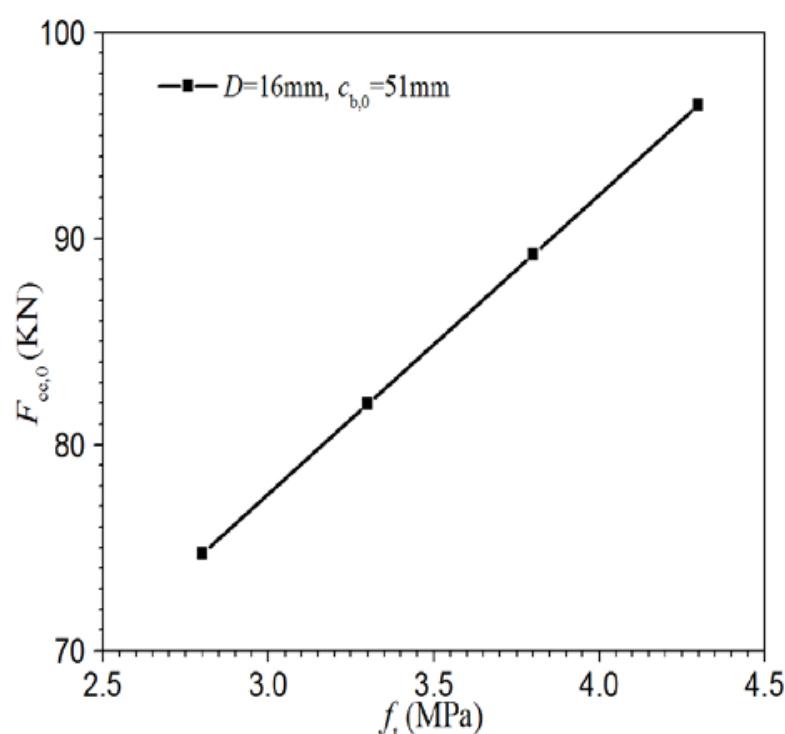

(d)

Fig. 7. Effects of $f_{\mathrm{t}}$ on (a) $P_{\text {rust,oc, }}^{\mathrm{C}}$ (b) $c_{\mathrm{b}, 0 \mathrm{c}}$, (c) $\gamma_{0}$, and (d) $F_{\mathrm{CC}, 0}$ 


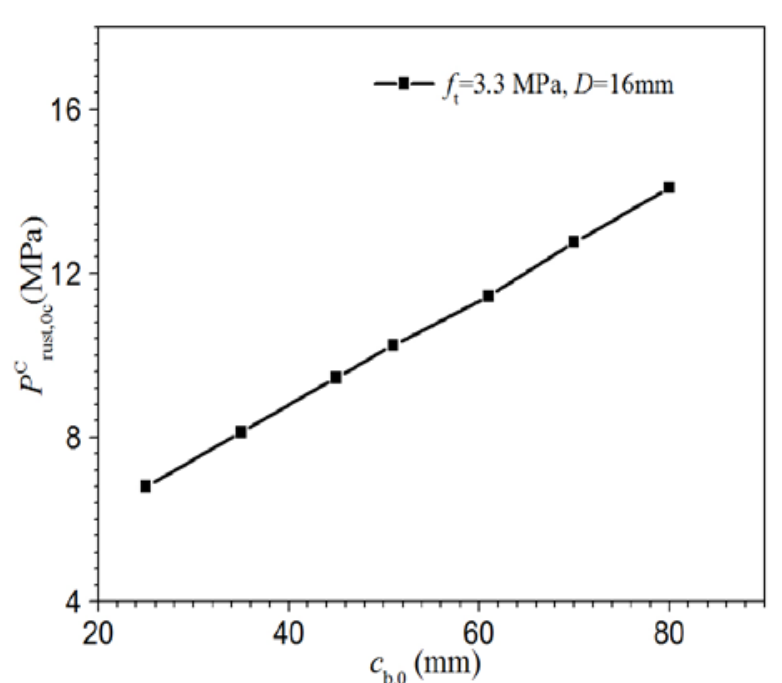

(a)

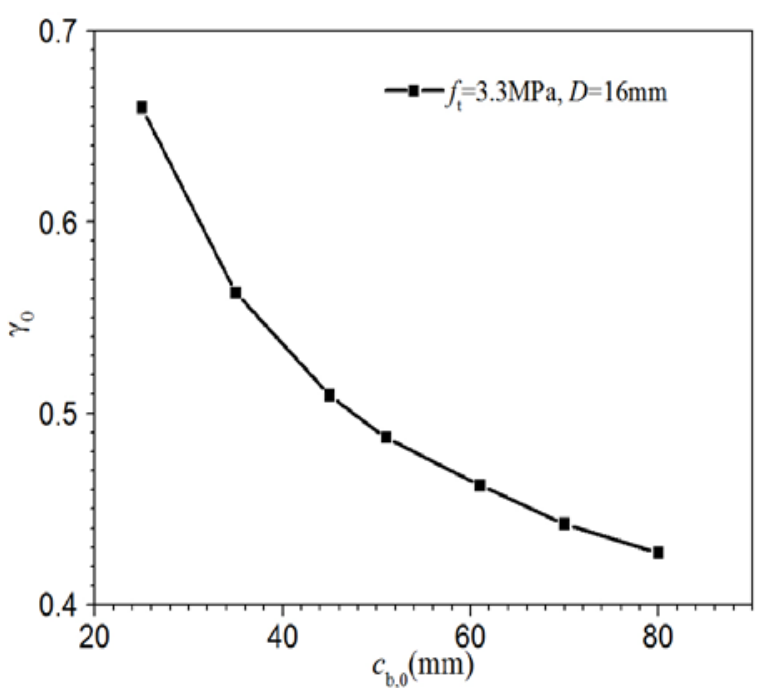

(b)

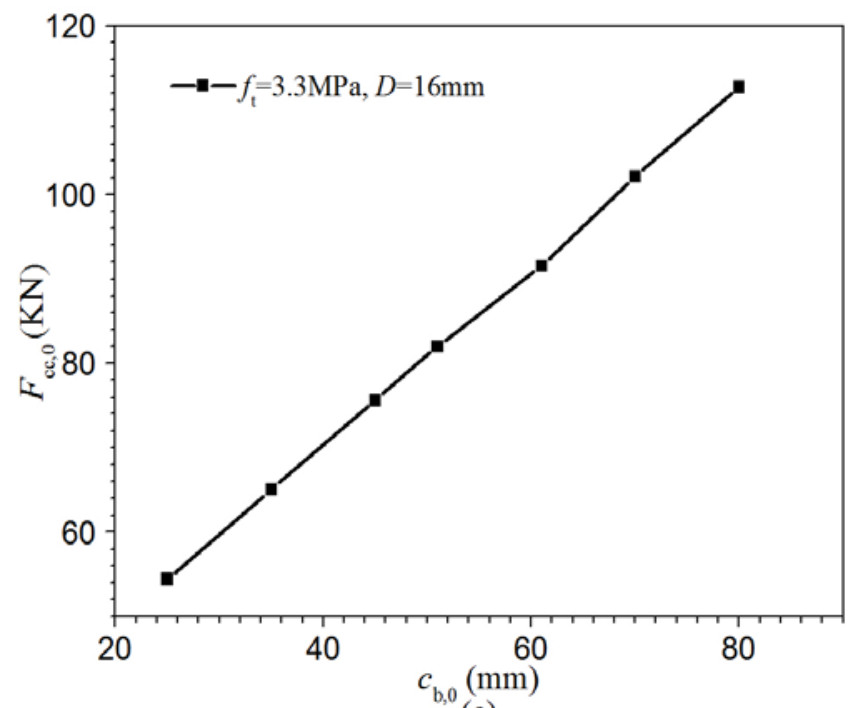

(c)

Fig. 8. Effects of $c_{\mathrm{b}, 0}$ on (a) $P_{\text {rust,oc }}^{\mathrm{C}}$ (b) $\gamma_{0}$, and (c) $F_{\mathrm{CC}, 0}$

1 